Document downloaded from:

http://hdl.handle.net/10251/123226

This paper must be cited as:

Llopis, O.; Sánchez-Barrioluengo, M.; Olmos-Peñuela, J.; Castro-Martínez, E. (2018).

Scientists' engagement in knowledge transfer and exchange: Individual factors, variety of mechanisms and users. Science and Public Policy. 45(6):790-803.

https://doi.org/10.1093/scipol/scy020



The final publication is available at

https://doi.org/10.1093/scipol/scy020

Copyright Oxford University Press

Additional Information 


\title{
SCIENTISTS' ENGAGEMENT IN KNOWLEDGE TRANSFER AND EXCHANGE: INDIVIDUAL FACTORS, VARIETY OF MECHANISMS AND USERS
}

\author{
Oscar Llopis a, *
}

Email: oscar.llopis-corcoles@esc-rennes.com

Mabel Sánchez-Barrioluengo ${ }^{\mathrm{b}}$

Email: mabel.sanchez-barrioluengo@ec.europa.eu

Julia Olmos-Peñuela ${ }^{c, d}$

Email: julia.olmos@uv.es

Elena Castro-Martínez ${ }^{\mathrm{d}}$

Email: ecastrom@ingenio.upv.es

${ }^{a}$ Rennes School of Business. 2 Rue Robert d'Arbrissel, 35065 Rennes (France)

${ }^{\mathrm{b}}$ European Commission. Joint Research Centre. Directorate Growth \& Innovation. Unit of Human Capital and Employment. Via E.Fermi, I-21027. Ispra (Italy).

c Department of Management, Universitat de València, Avenida Tarongers s/n, 46022 Valencia (Spain)

${ }^{\mathrm{d}}$ INGENIO (CSIC-UPV), Universitat Politècnica de València. Camino de Vera s/n, 46022. Valencia (Spain).

\footnotetext{
* Corresponding author. Email: oscar.llopis-corcoles@esc-rennes.com
} 


\begin{abstract}
This article aims to provide a deeper understanding of the individual factors behind scientists' involvement in a wide variety of knowledge transfer and exchange (KTE) activities. By doing so, the article addresses three major shortcomings in the literature. First, this paper considers scientists' involvement in both formal and informal KTE activities. Second, the study focuses not only on KTE activities with the private sector, but also with other types of agents. Third, the paper adopts an individual approach to distinguish between three types of KTE predictors: individual capacities, training and career trajectories, and research performance. Overall, the results of the regression model applied to a sample of 1,295 researchers active in the largest public research organization in Spain (CSIC) suggest that, while some individual features are connected to some KTE activities, other individual predictors (e.g.: multitasking and interdisciplinarity) are more evenly associated to a variety of KTE mechanisms and users. Based on those findings, the article offers policy recommendations to craft more accurate policies to encourage scientists’ KTE engagement.
\end{abstract}

Keywords: university-industry interaction, knowledge transfer and exchange, individual factors, mechanisms, users 


\section{Introduction}

The social role of public research has gradually evolved as the public authorities have identified the importance of new knowledge on the competitiveness of the productive sectors and other social activities (OECD, 1996 and UNESCO, 2005). Consequently, science and innovation policies have incorporated various mechanisms to facilitate and promote knowledge transfer and exchange (KTE) between scientists and social partners, especially firms. Researcher's evaluation, recruitment and incentive systems should evolve in parallel with this growing demand for social involvement (Jacobson et al., 2004). However, in many countries this transition has not been easy, and researchers' recruitment and promotion policies still give larger preference to scientific results - mainly in the form of academic publications - than to social impact. This is why a better understanding of the diversity of both the KTE mechanisms and the social agents involved as well as individual (antecedents and motivations of scientists) and institutional aspects affecting these processes can help to design tailored policies in favor of engagement in KTE activities.

The literature on KTE between researchers and social partners is extensive and comes from different fields (e.g.: sociology, economics, and political science). It also connects with a variety of multidisciplinary areas such as innovation studies (Bozeman, 2000; Carayol et al., 2005; Perkmann et al., 2013). Moreover, current research examines this phenomenon at different levels of analysis: the company, its strategies and characteristics, which determine their degree of willingness to collaborate (Vega-Jurado et al., 2008); the universities, their strategies and structures to facilitate interactions (Göransson et al., 2009; Jacobson et al., 2004; Laredo, 2007; O’Kane et al., 2015; Weckowska, 2015), the scientific and innovation policies and other framework conditions (Wolfgang et al., 2001) and scientists as individuals (Arvanitis et al., 2008; D’Este and Patel, 2007). The dominant focus within this extensive research stream on KTE has been on commercial mechanisms of research results (such as 
patents and spin offs) and on R\&D contracts (Meyer-Krahmer and Schmoch, 1998). However, recent contributions have started to analyze alternative knowledge transfer mechanisms, both formal (through the researcher's institution) and informal (Abreu et al., 2013; Landry et al. 2010; Olmos-Peñuela et al., 2014a).

In this paper, we focus on a set of individual-level antecedents which may influence the scientists' propensity to engage in different KTE mechanisms with non-academic actors. This micro-level approach is built on the agreement that scientists retain certain decision rights over the degree of interaction that they establish with non-academic actors, as well as the specific KTE that they select to do so (Tartari and Breschi, 2012). As recently pointed, "individual characteristics play an important role in predicting academic engagement" (Perkmann et al., 2013: 427). Moreover, there is accumulating evidence that researchers' engagement in various KTE activities is widely explained by individual factors rather than by their institutional context (Halilem et al., 2010).

In so doing, we do not restrict our approach to interactions with private agents, but we also consider interactions established with a larger variety of non-academic users (namely, public organizations and NGOs). Likewise, our focus on the individual scientist as the unit of analysis allows us to cover not only the formal KTE activities, but also the informal ones. This explicit consideration of informal KTE activities is particularly relevant, since they might fall "under the radar" when studies are conducted at the institutional level (Landry et al., 2010).

The remainder of the paper is structured as follows. Next section reviews the literature on diversity of KTE mechanisms and users as well as those individual characteristics affecting attitudes towards KTE activities identified in the literature. Section 3 provides a description 
of the research setting, the empirical data and methods. Section 4 describes and discusses results and section 5 draws conclusions, main limitations and policy implications.

\section{Literature review}

\subsection{Diversity of KTE mechanisms and users}

Despite the increasing attention devoted to the analysis of university-industry knowledge transfer, there are still at least two important limitations in the field. First, although research strives to provide evidence on the determinants of KTE, it generally does so by focusing on a few activities: the commercial ones (Agrawal, 2001). This is unfortunate, because recent research points out that collaboration between the academic and the societal spheres can take a myriad of forms (Bekkers et al., 2008; Landry et al., 2010). Second, the overwhelming part of the studies in the field has focused on the private sector (namely, firms) as the exclusive actors participating in KTE activities. More recently, the focus has broaden up to other social agents very relevant in specific contexts (Göransson et al., 2009) or fields (Landry and Amara, 2001; Esko et al., 2012). Both limitations are addressed below.

On the one hand, in the last decades, much of the research dealing with KTE mechanisms has been focused on commercialization activities such as patent, licenses or spin-off, largely due to the influence of US policies (Bayh-Dole Act, 1986) (Aghion et al., 2009; Mowery, 2011). While these perspectives have provided useful insights, more recent research highlights that KTE is composed by a broad spectrum ranging from 'soft' activities (advisory roles, consultancy, industry training, production of highly qualified graduates), which are closer to the traditional academic paradigm, to 'hard' initiatives such as patenting, licensing and spinoff activities (Philpott et al., 2011). In both cases, the dominant model focuses on narrow indicators, only counting formalized activities, that is to say contractual relationships between 
an academic unit and a non-academic agent in a way that creates a legal entity that can easily be traced. However, these institutionalized knowledge transfer activities (Geuna and Muscio, 2009) only represent a fraction of the universities' full suite of interactions with, and impacts upon, society (D’Este and Patel 2007; Perkmann and Walsh 2007) and ignore other (informal) collaborations that do not embody a legal relationship between the university and the user. Recent studies showed that informal links for knowledge transfer are also important, in particular in the case of social sciences and humanities (Olmos-Peñuela et al., 2014b). Therefore, ignoring them and focusing only on formal mechanisms could be a too narrow approach to provide a balanced and comprehensive perspective on KTE processes (Link et al., 2007; Abreu et al., 2009).

On the other hand, one of the most commonly used terms in scientific literature on knowledge transfer is "university-industry relationships" (Agrawal, 2001). The reason is that -although recently- the literature has opened its scope to a wider range of KTE mechanisms (D’Este and Patel, 2007; Bekkers and Bodas-Freitas, 2008), the focal point has mostly revolved around business actors. Research on interactions between scientists and social actors of other type (e.g.: Government sector, Private Non-Profit sector) is very recent and frequently within humanities and social sciences (Hughes et al., 2011; Olmos-Peñuela et al., 2014a). Powell et al. (1996) and D’Este and Perkmann (2011) pointed to the importance of cooperation with the private sector in life sciences and the physical and engineering sciences respectively, while Tartari and Breschi (2012) conclude that basic disciplines are less likely to cooperate with industry compared to applied disciplines such as engineering. Likewise, recent studies found that social science and humanities researchers engage with a wide diversity of partners, establishing more collaboration with public entities and non-profit organizations (Hughes et al., 2011; Olmos-Peñuela et al., 2014a, 2014c). Similarly, RamosVielba et al. (2016) find that motivations to cooperate are partly dependent on the type of 
partner organization involved, distinguishing between cooperation with government agencies and partnerships with firms. Recognizing the existence of diverse types of partner organizations is of outmost importance to refine our understanding of the determinants of KTE and design better policy interventions. With this aim, we propose to open up the knowledge transfer and exchange phenomena by explicitly considering two dimensions: the variety of mechanisms and the variety of users.

\subsection{Individual-level antecedents of KTE activities}

Extant literature has made reference to a wide range of individual level attributes to dig deeper into the micro-foundations of scientists' engagement in KTE activities. In this paper, we grouped individual attributes into four different categories: individual capacities, career trajectories, motivations and other factors. The following sub-sections are devoted to explicitly define the components of each category, as well as the empirical evidence supporting the connection between each category and the researchers' involvement in KTE activities.

\subsubsection{Individual capacities}

We conceive individual capacities as personal skills and knowledge-related tasks that might be connected to involvement in KTE activities. In particular, we focus on two antecedents: interdisciplinarity and multitasking.

Interdisciplinarity, at the most generic level, can be defined as communication and collaboration across academic disciplines (Jacobs and Frickel, 2009). The concept specifically refers to bridging research knowledge from different scientific domains, with the purpose of advancing fundamental understanding or solving problems whose solutions are beyond the scope of a single academic field (Porter et al., 2007). In science policy, 
interdisciplinarity has been regarded as a positive research approach that should be promoted. One of the aspects that have been encouraged to justify the relevance of interdisciplinarity is the fact that these approaches produce research results that are closer to address social needs or to more applied problems (Garner et al., 2012). For instance, Chavarro et al. (2014) found that more interdisciplinary academic publications tend to address local issues more often than disciplinary publications do so. Therefore, public research funders are increasingly running research funding programs with an explicit support to interdisciplinary approaches (Lyall et al., 2013).

Building on these ideas, our work explores whether scientists' interdisciplinary research collaboration influences their propensity to i) employ a variety of knowledge transfer channels, and ii) engage in knowledge transfer with a diversity of users. While other scholars have discussed the implications of interdisciplinarity in various aspects such as innovation (Schmickl and Kieser, 2008) or societal impact of research (Molas-Gallart et al., 2014), our focus is on the diversity of mechanisms and users. To explore these aspects, the way in which interdisciplinarity is defined is important. While some studies capture interdisciplinarity on the basis of the generated outputs of academics (namely, research publications) (e.g. Jensen and Lutkouskaya, 2014; Larivière and Gingras, 2010; Yegros-Yegros et al., 2015), our focus is on the diversity of collaboration partners. This approach is consistent to perspectives that view interdisciplinarity as collaboration between scientists from distinct disciplines (Cummings, 2005).

Our first contention is that those academics that collaborate more with scientists from different research areas will employ a higher variety of knowledge transfer mechanisms, compared to scientists who do not collaborate with academics from different disciplines. Because interdisciplinary research collaboration involves dealing with individuals from 
different fields, academics performing interdisciplinary research may develop a set of adaptive skills to cope with such diversity. Moreover, scientists may also employ these skills to successfully deal with the distinct demands required from different knowledge transfer channels (De Fuentes and Dutrénit, 2012). Our second contention refers to the variety of users. In this regard, we also expect a positive relationship between interdisciplinary research and the engagement with multiple non-academic user types. Because the resulting knowledge outcome from interdisciplinary research is likely to be closer to practical application (Chavarro et al., 2014), we expect that this impact is likely to be dispersed among a variety of users.

The second aspect that we consider in this category relates to the scientists' ability to perform different tasks simultaneously (multitasking). Complex or high pressure time conditions often requires individuals to allocate their attention to different activities, which is not always an easy endeavor for individuals due to the cognitive toll of task switching (Agypt and Rubin, 2012). This has been referred such as multitasking, or the capacity to switching among different tasks (Bertolotti et al., 2015). Multitasking is closely connected to ambidexterity, that is, the ability to reconcile activities related to exploration and exploitation (Good and Michel, 2013). Research indicates that “ by multitasking, employees are able to combine different types, sources and categories of relevant knowledge that reduce the tunnel vision of more functionally fixed individuals” (Schultz et al., 2013, p. 1357). In jobs characterized with knowledge intensive tasks, multitasking is a frequent feature (O’leary et al., 2011). In the case of academics, they often need to switch between different situational demands such as performing research activities, participating in teaching, dealing with administrative duties, disseminating research findings or other activities. Their many tasks often become intertwined upon one another, and scientists should deal with time constraints in order to manage them. 
We posit that scientists that exhibit a higher multitasking profile will be more likely to employ a higher diversity of KTE mechanisms and to reach a greater diversity of end-user through them. The main argument to support this claim is that multitasking reflects a scientists' ability to successfully manage a variety of demands. Additionally, reaching to a diversity of users also requires considerable flexibility, which will be better managed my multitasking scientists.

\subsubsection{Career trajectories}

We build on previous contributions to argue that scientists' career trajectories matter when explaining engagement in KTE. For instance, interaction with industry is likely to be contingent on scientists' career experience (Lawson \& Sterzi, 2014, Aschho \& Grimpe, 2014). However, literature offers ambiguous results about its effects. On the one hand, more experienced scholars tend to have more opportunities to interact with non-academic actors, since their accumulated human and social capital facilitates finding the right partners and developing the adequate skills to break the "ivory tower" (Haeussler \& Colyvas, 2011). On the other hand, it has been pointed that, since involvement with non-academic actors may contradict academic norms (Bercovitz \& Feldman, 2008), more experienced researchers may find very difficult to adapt their mindset to the expectations and norms required to develop non-academic partnerships. Thus, less experienced scientists might be more ready to adopt non-academic norms and procedures and hence, to have more interactions with actors located beyond the academic boundaries.

Empirical studies indicate that having no experience in non-academic sectors is negatively associated to researchers' engagement in both formal and informal KTE activities (Abreu and Grinevich, 2013). Conversely, researchers with previous' experience outside academia may engage through different knowledge transfer mechanisms that may vary depending on the type of non-academic sector where they had previously worked. Thus, previous research 
points that researchers with prior experience in the public sector participate more in contract research and informal activities, whereas researchers with experience in the third sector are more engaged in consultancy, contract research and informal activities. Likewise, researchers involved in small companies participate more in consultancy and informal advice, whereas those that owned a company before their academic career are more engaged in all the types of knowledge transfer activities (Dietz \& Bozeman, 2005; Abreu \& Grinevich, 2013). Additionally, literature highlights that previous experience outside academia may help to build relational assets creating opportunities to engage in knowledge transfer activities with non-academic users (Landry et al., 2007, 2010).

Academic researchers' quality and its relations with researchers' engagement in KTE activities has been the subject of extensive research in the last years (Manjarrés et al., 2008, 2009; Haeussler and Colyvas, 2011). This interest stems from the potential tensions that arise from the traditional vision of the university - encouraging researchers to publish in scholar outlets - and the entrepreneurial vision of university - promoting researchers' engagement in commercialisation activities (Landry et al., 2007). As noted by a recent review conducted by Perkmann et al. (2013), most of the empirical research to date suggests that researchers demonstrating higher levels of research performance are those more engaged in knowledge transfer activities (Gulbrandsen and Smeby, 2005; Bekkers and Bodas Freitas, 2008,; Haeussler \& Colyvas, 2011), thus indicating that "knowledge transfer activities of university researchers did not jeopardize their scientific activities” (Landry et al., 2007: 585). This positive relationship points to complementarity effects between public and private science (Powell \& Owen-Smith, 1998; Landry et al., 2010). Measures of research performance traditionally consider research quality in terms of number of researchers' publications in scholarly journals (Schartinger et al., 2001), citations to publications (D'Este et al. 2012) or the identification of "star scientist” researchers (Zucker et al., 1998; Olmos-Peñuela et al., 
2014c). Another indirect measure of research performance may consider individuals' obtaining resources granted on the bases of its research performance (e.g. grants for $\mathrm{PhD}$ supervision, competitive projects, etc.). For example, we contend that competitive funds (i.e. economic funds gained in public competitive concourses) may affect researchers' engagement in KTE because they might have a substration effect with private funds. Due to the recent changes in public budgets, researches have the necessity to look for alternative economic sources to develop their own research activities and there has been a promotion of collaboration between universities and multiple partners through a range of public policies and infrastructure (Abreu and Grinevich, 2013; Miller et al., 2014).

Drawing on this literature, we contend that researchers' past experience, -in terms of their professional experience and academic quality-, may influence the KTE activities and thus the variety of mechanisms employed and the diversity of users with whom they engage. This argument is backed on the fact that previous experience may allow researchers to cultivate an extensive and diverse social network, which will subsequently facilitate their engagement with diverse users through a variety of channels.

\subsubsection{Motivations}

Another aspect that may influence both the diversity of KTE mechanisms and users refers to individual motivations. KTE literature provides abundant evidence on the role of scientists' motivations in their decision to interact with non-academic agents. For instance, Lam (2011) distinguishes between three main motives underlying academics’ participation in knowledge transfer: "gold” (financial rewards), "ribbon” (reputational/career rewards) and "puzzle” (intrinsic satisfaction) finding a significant degree of heterogeneity between scientists. Scientists are also driven to engage with industry by more utilitarian motives, such as getting resources (financial or material), income or learning (D’Este and Perkmann, 2010). In 
addition, Iorio et al. (2017) highlight the importance of the "mission" motivation, which has a positive effect on the variety and intensity of KTE activities in the case of Italian researchers. Despite this increased focus on the role of individual motivations to explain the scientists' engagement in knowledge transfer activities, most studies have focused on one -or few- of them, but have not explicitly explored the effect of distinct motivations over the diversity of mechanisms and users. Although we do not make any specific prediction about the particular motivation type that may be more strongly connected to either the diversity of mechanisms or users, existing evidence suggest that motivations play a role in shaping scientists' knowledge transfer decision. Hence, we expect motivations to be significantly correlated to both aspects.

\subsubsection{Other antecedents}

We now turn to additional antecedents that may be connected to KTE activities. At the individual level, scientific field, gender and seniority have been traditionally studied in the literature. For example, D’Este and Patel (2005) find that disciplinary variables are significant in determining the variety of scientific interactions. Similarly, Lee (1996) also finds a positive relation between faculty members in engineering and technological disciplines and the support for the objectives of collaboration with firms. However, Schartinger et al. (2002) show a greater propensity of researchers to interact in natural, technical, farming and economic sciences than in medicine, other social sciences and humanities. Specifically, Olmos-Peñuela et al. (2014c) found that social sciences and humanities research groups collaborate with non-academic partners on knowledge transfer activities, including consultancy, contract research, joint research projects and training and Castro-Martínez et al. (2011) that these fields are closely linked to community users such as non-profit organisations, as shown in the Spanish context. Related to gender issues, men have more research collaborators than women (Bozeman and Corley 2004; Lee and Bozeman 2005), although more recently Bozeman and Gaughan (2011) found no difference in the 
number of collaborators by gender in US. There is also some evidence that women tend to collaborate more with other women in universities (Boardman and Corley 2008) and professional networks (Ibarra 2003). This pattern also chimes with the result that male academics are more likely to engage with industry, mirroring the insight obtained from other studies suggesting that male scientists occupy more prominent positions than women and are hence in a better position to mobilise resources and establish wider networks (Gupta et al., 2005; Murray and Graham, 2007; Best et al., 2016). On the other hand, several empirical studies addressing the effect of seniority into researchers' engagement in knowledge transfer activities agree about the positive relationship between academic experience and both informal (Link et al., 2007; Abreu et al., 2013) and formal (Boardman \& Ponomariov 2007, Ponomariov, 2008; D’Este \& Perkmann, 2011) collaborations with non-academic parties. This positive relationship might be explained by different factors. First, the higher relational capital that more experienced researchers have already built along its academic career; second, the well-established position of those researchers that hold the highest academic position (i.e. research professors) that may attract non-academic actors' interest to collaborate; and third, the less pressure that research professors feel to publish (since they have already reach the maximum position in their career) that leaves them more time to engage in collaborative activities with users compared to researchers in a lower academic position (Louis et al., 1989, Stephan \& Levin, 1992 , , Giuliani et al., 2010). At team level, the size of the department influence the scope of the activities carried on. As largely demonstrated, department size affects researchers' scientific production (Kyvik 1995; Bonaccorsi and Daraio 2003), unit size also significantly explains knowledge transfer in the majority of the research fields (Landry et al, 2007).

All the factors explained here are employed in the empirical section of this paper to understand more in detail what antecedents have a stronger effect on KTE activities. 


\section{Data and methods}

\subsection{Context}

The empirical study focuses on the Spanish Council for Scientific Research (CSIC), the largest public research organization in Spain, which employed 14,050 workers within the 126 research institutes located throughout the Spanish territory. CSIC research institutes are distributed in eight fields of knowledge: Biology and Biomedicine; Food Science and Technology; Materials Science and Technology; Physical Science and Technology; Chemical Science and Technology; Agricultural Sciences; Social Science and Humanities; Natural Resources (CSIC, 2012). Despite representing 6\% of the human resources engaged in R\&D in Spain, CSIC produces $20 \%$ of the international scientific publications, since the main aim of this public organization is developing and promoting research leading to scientific and technological progress. Unlike university researchers, teaching duties are not compulsory among CSIC researchers, being research, knowledge transfer and dissemination the main activities expected from them.

Due to particular characteristics of this institution, we summarize here some of them in order facilitate the understanding of the context. Researchers working at CSIC might be classified according to whether they are civil servants (those belonging to the scales of researchers of public research organizations) or temporary employees (usually with a contract between 3 and 5 years). All of them are affected mainly by the Spanish Law of science enacted in 2011 but particularly civil servants are also affected by various general laws or regulations influencing their daily work: i) there is a limit number of teaching hours they can teach annually (70); ii) there are restrictions to participate (less than 10\%) in those firms' ownership related to their activity that can establish contracts with the State; iii) the inability to directly receive remuneration from private activities (since civil servants have full time 
dedication). In addition to that, significant bureaucratic charges also deter time for research and KTE engagement.

In any case, the Spanish scientific policy promotes the exchange and transfer of knowledge with the social agents, and this objective is included among the main functions of the CSIC (statute). The sixth National Plan for Scientific Research, Development and Technological Innovation developed by the Ministry of Economy and Competitiveness (in force when the survey was carried out in 2011) declare as one of its main objectives "to put research at the service of citizenship, social welfare and sustainable development, [...] making research a factor for the improvement of business competitiveness". This National Plan had a specific program aimed at developing these objectives (the National Plan of technology transfer, valuation and promotion of technology-based companies).

Regarding CSIC recruiting and internal promotion policies, scientists are primarily evaluated in terms of their academic publications, their competitive funding performance and, to a much lesser extent, the social dimension of their activities. Activities related to the social dimension are taken into account when evaluating research groups and research institutes' performance. This assessment is considered for the distribution of resources, infrastructure and opening positions for new researchers. These external factors together with the researchers' own motivations (D'Este and Perkmann 2011; Olmos-Peñuela, 2015) gives rise to a significant activity of the CSIC researchers in KTE processes as the data presented in this study will show.

\subsection{Research population}

To test our conceptual model, data for our analysis was gathered within the framework of the IMPACTO project commissioned in 2011 by the CSIC and aimed at exploring the 
relationships established between CSIC researchers and non-academic actors. Specifically, data was collected between April and May 2011 using a questionnaire structured in five sections addressing aspects related to researchers' profile, engagement with non-academic actors (including information about mechanisms, types of actor involved), motivation and barriers for engagement and results of these engagement activities. The questionnaire was sent to the 4,240 researchers (civil servants and contracted researchers) working at CSIC identified by the human resources department as researchers with a doctoral degree and the right to be involved in contracts and agreements with third parties as principal investigators. Online questionnaires were sent to these researchers and telephone follow-up were conducted to achieve sample proportionally distributed by scientific fields and rank levels. ${ }^{1}$

We obtained a response rate of $37 \%$ which accounted for more than 1,500 researchers. In this study we are interested in those researchers holding a permanent position in the CSIC (i.e. civil servants). As research activities and outputs (research projects and publications in wellrecognized academic journals) are the main factor for career promotion at CSIC, we argue that contracted researchers that have not reached the highest position are more interested in focusing on these research activities than in engaging in KTE activities. Since this study addresses researchers' engagement in KTE, we have chosen to focus on those researchers with a permanent position which allows for a more homogeneous sample. Thus, the final sample used in this study is 1,295 researchers. The distribution of these researchers across field is presented in Table 1.

[Insert Table 1 about here]

\subsection{Variables}

\footnotetext{
${ }^{1}$ For further information about CSIC organization and data collection see Olmos-Peñuela et al. (2014a).
} 


\section{Dependent variables.}

The dependent variables of this study cover a broad range of KTE mechanisms (forms of engagement) and a broad range of non-academic actors (users) with whom researchers engage through these mechanisms. We developed two different, yet related indicators of KTE. We draw upon the methodology proposed by Bozeman and Gaughan (2007) “industrial involvement scale index” to capture two different aspects related to the scientists' interaction with non-academic actors: "mechanisms variety” and "users variety”. Concerning the former, mechanisms variety is grouped into two modes distinguishing the type of engagement occurred: formal and informal mechanisms variety. To build the mechanisms variety indicator, respondents were asked to report whether, in the last three years, they have been involved at least once in any of the 14 knowledge transfer mechanisms proposed in the questionnaire (dummy variable). We then categorized all 14 mechanisms in the two above mentioned categories of formal and informal type (Table 2). Concerning users variety, we asked respondents to report to what extent they had engaged in knowledge transfer activities with three types of national and international non-academic actors (also dummy variable): i) private sector, ii) public organizations and iii) NGOs. Table 2 establishes the relationship between original questions in the questionnaire and the groups used in this study.

\section{[Insert Table 2 about here]}

Then, for every type of activity (mechanisms variety) and type of user involved in the interaction (users variety) we established whether the researcher had engaged or not ('occurrence', denoted by $b_{j}$ ). We start from the information at individual level about researchers' engagement and we use this information to calculate the occurrence rates for each mechanism that will be used to build our dependent. We computed the frequency of 
academics' use of each type of engagement and user for the whole population in the following way:

$$
f_{i}=\frac{\sum_{n=1}^{N} b_{n, j}}{N}
$$

where $\mathrm{j}$ is the type of mechanisms used in the first case $(\mathrm{j}=1, \ldots, 14)$ and the type of actor involved in the second case $(\mathrm{j}=1, \ldots, 5), \mathrm{n}$ is the individual and $\mathrm{N}$ is the total sample. We then constructed the mechanisms and users variety indexes (quantitative variable) by summing the frequency of its non-occurrence $(1-\mathrm{fj})$ as follows:

$$
\text { Index }=\sum_{j=1}^{J}\left(1-f_{i}\right)
$$

To give an example, $12.5 \%$ of the sample reports having participated in the creation of a new center or joint unit of $R \& D$ (see Figure 1) and, thus, engaging in that activity receives a weight of 87.5 . Similarly, $84.4 \%$ of the sample report having occasional contact or consultations with non-academic actors and, thus, engaging in that more common activity receives a weight of 15.6. The same logic also applies to the user index (Figure 2). For example, $80.1 \%$ of researchers engage with national firms and in consequence, the weight applied will be $19.9 \%$. Using the same explanation as the authors in their paper, we consider that this approach is useful because standard measurement theory suggests that items "more difficult” (in a behavioral or psychological sense) should receive stronger weight than those “less difficult.”

This methodology allowed us to calculate two indexes for mechanism variety and users variety with a Cronbach alpha of 0.79 and 0.54 respectively $^{2}$. In addition, there are two variables related to KTE mechanisms: formal versus informal mechanisms calculated in the

\footnotetext{
${ }^{2}$ Cronbach’s alphas are 0.64 for formal engagement and 0.69 for informal engagement.
} 
same way as explained before but including only those mechanisms of each type (see Table 2 Panel A). All these indexes are used separately as dependent variables in the regressions.

\section{Independent variables.}

In order to understand what are the individual-level antecedents which may influence the scientists' propensity to engage in KTE with non-academic actors, the paper focuses in a set of antecedents, namely: individual capacities, career trajectories and motivations to engage.

Specifically, individual capacities of researchers for KTE activities are measured trough two variables: interdisciplinarity and multitasking. The variable related to interdisciplinary is based on a survey question. Specifically, we asked respondents to indicate how frequently they develop their scientific research activities with scientists from other disciplines. Interviewees had three alternative options of response: a) Frequently; b) Occasionally; and c) Never or hardly ever. This last option will be used as a reference category. On the other hand, the variable multitasking captures the concentration or dispersion of tasks a researcher should be involved and is calculated on the basis of a survey question. Specifically, the question asked scientists to indicate the percentage of time they allocate $\left(\mathrm{p}_{\mathrm{i}}\right)$, during a regular week, to the following activities: i) research; ii) administrative duties; iii) teaching; iv) connections with other non-academic entities; v) dissemination of research findings; and vi) other activities. Then, we calculated a Herfindahl index to account for the diversity of activities performed by each scientist by applying the following formula:

$$
H=1-\sum_{i=1}^{N} p_{i}^{2}
$$


The Herfindahl index $(\mathrm{HH})$ takes positive values starting in 0 . In our case, values closer to 0 indicates a high degree of task concentration, while highest values reflect more task diversification.

Career trajectory is captured by measuring previous experience of researchers, research performance, supervision experience and competitive funds obtained. We included three variables related to the scientists' previous experience: previous experience at the university, previous experience at the private sector and previous experience at the public administration (excluding research organizations). To gather this information, we asked respondents to report their previous experience (in years), before being formally appointed as CSIC researcher. These variables are used here in logarithms to avoid biased results. Due to the particular characteristics of the Spanish research evaluation system, research performance is measured through number of "sexenios" and the supervision experience of the researcher. Sexenios are a salary supplement which results from a research evaluation process (Osuna et al., 2010) based on the examination of individual research output over a six-year period, with the identification by the applicant of five important research contributions (journal papers, books and/or patents). If the evaluation is positive, the researcher receives a sexenio and the immediate effect of succeeding in the research evaluation for a researcher is an average increase, depending on their academic category, of $€ 190$ to 230 in their monthly salary for each positive evaluation (sexenio). Sexenios have a reputational value and influence the access to other resources and rewards, such as project grants or professional career advancement. In this study we include the number of sexenios a researcher has achieved in logarithms. In addition, the supervision experience of the researcher is measured by the number of students with public-competitive grants to obtain the $\mathrm{PhD}$ certificate that a 
researcher has supervised ${ }^{3}$. Among the merits evaluated to obtain these public grants it is included the CV of the supervisor, that is, having a better CV increases the probability of the student to obtain a grant to do the $\mathrm{PhD}$. This variable is also transformed in logarithms for its use in this work. Competitive funds are calculated as the amount of competitive funds (in Euros) that the respondent has received in the last three years (continuous variable in logarithms).

Finally, the last group of individual antecedents accounts for motivations to be involved in KTE activities. We have three variables to measure motivations coming from the questionnaire. To conceptualize the expected benefits to interact with non-academic users, respondents were explicitly asked to rate in a Likert scale ranging from 1 to 4 a set of reasons about why they would interact with non-academic users. Examples of these reasons are "to obtain additional funds for my research" or "to access to the experience and resources of professionals from my academic field”. Using a factor analysis technique with varimax rotation and Kaiser normalization, items were grouped into three categories: advancing research, expanding network and obtaining income. Each category was calculated using the factor scores of the factor analysis. Table 3 summarizes the results of this factor analysis.

[Insert Table 3 about here]

\section{Control variables.}

Additional controls are included in the regressions: scientific rank, size of the research group, gender and field. Scientific rank controls for the hierarchical position of the respondent with three alternative possibilities: tenured scientist (científico titular), scientific researcher (investigador científico) and research professor (profesor de investigación) been the highest rank. The first type will be used as reference category. Size research group is a continuous

\footnotetext{
${ }^{3}$ Public grants to obtain the PhD refer to JAE, FPI, FPU and similar.
} 
variable indicating the total number of members belonging to the same research group as the respondent (in logarithms), gender is a dichotomous variable taking the value 1 if the respondent is a female, 0 otherwise and, finally, the eight areas in which CSIC is divided to capture the research field (with humanities and social science as reference category).

Annex I includes the correlation matrix evidencing the low-correlation between independent variables as a symptom of the absence of multicollinearity problems. There is only one medium correlation between rank and sexenios variables (0.62). In order to guarantee that this is not introducing any problem in the regression analysis, we additionally included the variance inflator factor (VIF), which is the inverse of the tolerance statistic values. We observe that VIFs results are below the value 10, which is usually used as a rule of thumb to determine that there are no multicollinearity problems (Field, 2009).

\section{Results}

\subsection{Descriptive results}

Before moving to the regression results, this section includes some descriptive statistics in order to characterize the sample of respondents. On average, respondents have been more involved on informal activities (60.3\%) than on formal activities (35.6\%). This result is in line with previous research analyzing the Spanish case that suggests the importance of informal activities (Olmos-Peñuela et al., 2014b) although not only in the field of social science and humanities. Figure 1 summarizes the engagement on each type of activity, according to the responses to the questionnaire. In this case, occasional contacts or consultations are the most frequent KTE mechanism used with more than $80 \%$ of researchers been involved. This is followed by collaborative research funded by a Spanish public program (projects in collaboration with non-academic agents) where $78.5 \%$ have participated. 
Conversely, the least frequent KTE mechanisms are the creation of a new firm in partnership and the participation in the creation of a new center or joint unit of $R \& D$ (with $3.6 \%$ and $12.5 \%$ of researchers involved respectively).

Comparing the results by type of user involved in the KTE process, researchers slightly have more partners from the private sector (64.8\% on average) than from public organizations (63.4\%), while half of the sample (50.3\%) mentioned engagement with non-profit organizations. Similar figures about the engagement with private and public users reinforce the idea of the myopic view exhibited by the studies focusing only in the private sector as main non-academic partners involved in KTE processes (Ramos-Vielba et al., 2016). Figure 2 summarizes these results and suggests that national partners are more frequent than international counterparts (around $80 \%$ of national versus less than $50 \%$ in the case of international partners), and specifically, the most frequent user involved on engagement activities are national firms (80.1\%).

[Insert Figure 1 about here]

[Insert Figure 2 about here]

Finally, we describe all other researchers' individual-level characteristics. In terms of the individual capacities, half of the researchers mainly consider their research as interdisciplinary “occasionally”. In general terms, researchers exhibited a quite high diversification in their activities: $50 \%$ of obtained an inverse $\mathrm{HH}$ index above 0.53 while the maximum of the distribution locates in 0.795 . Related to their career trajectories, their main previous experience has been in other universities, with an average of 3.4 years, while on average they have been working in the private sector or in other public organizations less than a year. On average, they have received 2.7 sexenios, supervised $2.2 \mathrm{PhD}$ students with public competitive grants and around $82 \%$ of their funds come from competitive projects. 
Motivational variables are rather difficult to interpret due to the way they were measured. In general terms, higher values reflect stronger motivation towards the particular activity. Moreover, data reflects that the average research group size is 8.6 people. Concerning seniority, $44 \%$ of them are tenured scientists, while less than $23 \%$ are at the top category as research professors. Finally, it is worth noting that our sample is a bit skewed towards males, with only $35.1 \%$ of the sample being female researchers.

\section{[Insert Table 4 about here]}

\subsection{Regression results}

Following Bozeman and Gaughan (2007), we employed an ordinary least squares (OLS) model to investigate the influence of individual factors on academic researchers' interactions with industry. The use of OLS assumes a normally distributed dependent variable: therefore, we employ the logarithm of the academic engagement index. To address possible heteroschedasticity problems, we use robust standard errors following the work of Tartari et al. (2014). Another assumption of OLS is that standard errors are independently and identically distributed; however, this can be violated. If the errors are clustered (i.e., if the observations within a certain group are correlated in unobservable ways), the OLS estimates will be unbiased, but the standard errors may be wrong, leading to incorrect inferences. Since the respondents in our sample are affiliated to different fields, we can expect some group correlation which we are not able to observe; therefore, we clustered errors by scientific fields.

Table 5 presents the results of our OLS regression analysis for mechanisms (first column) and user varieties (fourth column) as well as for the sub-indexes of formal engagement (second column) and informal engagement (third column). First, our analysis reveals that individual capacities exert the greater effect on the variety of both KTE mechanisms and users. 
Specifically, higher levels of interdisciplinarity lead to greater variety of KTE mechanisms and users. Similarly, our results point to the idea that multitasking is a positive predictor of greater variety of KTE mechanisms, confirming the notion that more multitasking scientists are better equipped to reach a larger variety of users, and to do it in multiple ways.

Concerning the career trajectories, results indicate that previous experience in public organizations is positively associated to engaging in a higher variety of both formal and informal KTE mechanisms. This suggest that experience in public administration and other advisor or political organizations help researchers to be more aware of the usefulness that scientific knowledge may have over decision-making and public management. This result contrasts with the effects of previous experience in universities and private sector, which appear to have no significant association with KTE mechanisms variety (even negative, in the case of university experience). Our results do not fully align to previous empirical evidence. Indeed, Abreu and Grinevich (2013) found that engagement in a higher variety of KTE mechanisms is more manifested among those researchers who owned a firm before entering into the academic career, but not among those having previous experience in public organisations. Such differences across studies may be attributable to the way in which previous experience was captured. While Abreu and Grinevich (2013) distinguish among three types of previous experience within the private sector (involved in a large company, in a small company or owning a company), our study does not make this distinction. On the other hand, incompatibility laws affecting civil servants in Spain may play a role in shaping such external activities.

Among the set of considered motivations, "expanding the network" appears to have a positive and significant influence on all forms of KTE mechanisms. We observe a weaker effect for the motivation related to "obtaining income", and even weaker for "advancing research" 
being only significant at $10 \%$. The influence of the last two motivation types relate to the type of mechanisms variety. While being motivated by "advancing research" is a determinant of formal engagement variety, “obtaining income” only relates to informal variety of mechanisms. The first result could be explained by the fact that scientists are prompted to formalize their collaborations through specific projects, in order to agree on the conditions and requirements and, in many cases, to receive public funding from programs promoting innovation. The second result may respond to the peculiarities of the CSIC context. While receiving additional incomes from $\mathrm{R} \& \mathrm{D}$ contracts is legally complex, payments coming from conferences or courses are easier to deal with; even though the maximal amount is legally limited.

Results also indicate that research performance has different effects over formal and informal mechanisms variety. Specifically, experience in supervision tasks only relates to informal engagement variety which could be explained by the relational assets that researchers may build through their students (Landry et al., 2007, 2010). Such informal assets may open up the possibility to engage in informal conversations and collaborations with stakeholders interested in students' research and its potential benefits. Finally, it is interesting to note that, for informal KTE activities, gender is not a significant variable, being the only case where being a male is not significantly influencing the variety of KTE mechanisms. Our results corroborate then that men have more research collaborators than women (Bozeman and Corley 2004; Lee and Bozeman 2005) but particularly in the case of formal mechanisms, while this gender difference does not apply in the case of informal KTE mechanisms.

The last column of Table 5 shows results of the OLS regression when considering "users variety”. That is, the diversity of non-academic actors with whom our respondents have interacted during the last three years. As in the previous case, multitasking is positively 
linked to the variety of users, pointing to the idea that scientists who are more familiarized to work with colleagues from other domains are better equipped to interact with diverse nonacademic actors. Similarly, the higher the diversification of tasks is, the higher their capacity to vary their portfolio of partners. A mix of results appears for the career trajectories antecedents. Higher supervision experience and having previous experience in public organizations as well as having the highest academic rank (being a research professor) positively affects the probability of engaging with a higher diversity of users. However, greater scientific performance (measured through sexenios and competitive funds) negatively influences the variety of users. Obtaining sexenios (evaluation of research quality) or getting competitive funds (evaluation of research projects) are activities mainly circumscribed within the research sphere that do not necessarily imply interactions with users. However, as explained before, the supervision of $\mathrm{PhD}$ students could be a source of new networks allowing the researcher to expand its relational assets through the new stakeholders contacted or known by the PhD student, thus increasing the likelihood of the researcher to increase the variety of users with whom to collaborate (Landry et al., 2007, 2010). Likewise, higher experience in both the non-academic sector (e.g. public organisation) and the academic sector (rank) may allow the researcher to progressively build a more diversified portfolio of nonacademic partners, resulting in a larger network for potential collaborations (Giuliani et al., 2010; Haeussler and Colyvas, 2011). Similarly, research professor that already hold the highest academic rank may feel less pressure to devote time to activities different from publishing, thus been more prone to establishing contact with a higher diversity of nonacademic actors, or may be more acknowledge by external entities who may rely more on them. In terms of motivations, we observe that “advancing research" and "expanding networks” are important motives to interact with a higher variety of users. Finally, our results evidence that not only male academics are more likely to engage with industry (Murray and 
Graham, 2007), they have also a higher probability of having a wider portfolio of users to engage with.

[Insert Table 5 about here]

\section{Conclusions and implications}

Literature dealing with KTE activities has traditionally focused on scientist' interactions with the business sector, while has disregarded other type of potential users. Likewise, the analysis of KTE activities has been limited to a range of mechanisms, namely formal commercial activities that are formalized and easy to count. Another issue is that individual characteristics have been underplayed in researchers' decision to engage in KTE activities in a (scientific) context where scientist have a large autonomy to take decisions regarding research agenda and collaborations.

This study covers these three relatively understudied issues by adopting a micro-level approach to address researchers' engagement in KTE activities. We show that the combined study of individual characteristics with the variety of mechanisms and users provides a deeper understanding of the KTE activities, which may have a direct application in scientific and institutional policies, including scientific assessment systems.

We analyzed the role individual-related factors: individual capacities (interdisciplinarity and multitasking), career trajectories and motivations. Interdisciplinarity and multitasking are strong predictors of the willingness of scientists to be involved in a wide range of activities and with diverse types of users interested in their knowledge. Previous experience in the public sector influences positively on the variety of mechanisms and users, which could be taken into account in academic recruitment systems, thus encouraging careers in which the 
researcher enters and leaves the scientific system rather than staying exclusively in their (ivory tower) scientific career.

Regarding motivations, obtaining income is related to informal mechanisms while advancing research to formal ones. This result may be due to the fact that income from conferences or courses, although having legal limitations, are directly received by the researchers, while obtain those coming from contract research or consulting must to be done through CSIC with strict restrictions. The second result is explained by the need to establish conditions for the development of activities of high scientific level and the access to public funds for innovation, which is of general application. Many KTE mechanisms are informal by nature (committee memberships, advisory in parliament or other public entities, conferences and courses, etc.), since the user entity establishes direct contact with the researcher. In these cases, scientific entities cannot claim to control all this activity, but they may gather information about them if they have systems to collect appropriate information. This is particularly true in cases where these activities as part of the social dimension of researchers and, consequently, of the institution itself.

The negative influence of scientific performance on researchers' involvement on a higher variety of mechanisms and users suggests that the pursuit of scientific quality is difficult to reconcile with the amplitude of social relevance. This may be due to the difficulties of managing a complex agenda, as well as the difficulties inherent to a context of low scientific and technical capacity as the Spanish one. In this case of incompatibility of tasks, organisations should readapt their incentive policies to the promotion of the activities expected to be conducted by the researcher, which include KTE activities if the organisation is committed to deal with its social dimension. 
We acknowledge that the use of this database imposes some limitations on the generalizability of our findings. First, the database only includes CSIC researchers. Although focusing on a single institution allows us to obtain a homogenous population, subject to the same contextual conditions, the inference of the results is limited. In this regard, more research is needed to replicate this work in different institutional settings and in additional national contexts. Second, all scientific fields are not equally represented in CSIC. However, the fact that some areas of knowledge have a stronger presence than others is a common feature in academic organisations. Due to the self-reported answers to the questionnaire, different interpretations of the questions could appear depending on the field. Third, measures and variables used in this study corresponds to traditional formal and informal mechanisms and users addressed in the literature to capture knowledge transfer and exchange activities; however other activities (mainly informal mechanisms such as participation in expert committees) might be used by researchers as part of their KTE portfolio. Additional studies should analyse a broader and alternative frameworks in order to enrich the results presented here. Overall, we consider that despite these limitations, it is still reasonable to propose using the CSIC database as the foundation for our exploratory analysis.

Finally, the scientific and policy implications derived from our findings need to be interpreted with caution since the analysis has been conducted in the Spanish context, where the political and institutional policies may differ from other countries and context (e.g., restriction on additional incomes). Thus, individual attitudes towards KTE activities may be influenced by contextual conditions, an issue that we cannot control for with our sample but that further research should address through transnational studies.

\section{Acknowledgements}


The empirical activity of this work was supported by the Spanish Council for Scientific Research (CSIC) through the IMPACTO project [Ref. 200410E639]; the authors acknowledge CSIC and other IMPACTO project researchers (INGENIO and IESA) for their work and the CSIC researchers whose answers to the questionnaire enabled us to develop the database. The authors acknowledge the financial support received from the Ministry of Economy and Competitiveness (Ref.: CS02013-48053-R ). The views expressed here are those of the authors and in no circumstance should be regarded as representing the official position of the European Commission.

\section{References}

Abreu, M., Grinevich, V., Hughes, A. and Kitson, M. (2009) Knowledge Exchange between Academics and the Business, Public and Third Sectors. London: UK Innovation Research Centre, University of Cambridge and Imperial College.

Abreu, M. and Grinevich, V. (2013). 'The nature of academic entrepreneurship in the UK: Widening the focus on entrepreneurial activities’. Research Policy, 42/2: 408-422.

Aghion, P., David, P.A. and Foray, D. (2009) 'Science, technology and innovation for economic growth: Linking policy research and practice in "STIG Systems'. Research Policy, 38/4: 681-693.

Agrawal, A.K. (2001) 'University-to-industry knowledge transfer: Literature review and unanswered questions’, International Journal of Management Reviews, 3/4: 285-302.

Agypt, B., Rubin, B.A., (2012) 'Time in the New Economy: The Impact of the Interaction of Individual and Structural Temporalities on Job Satisfaction: Time in the New Economy.' Journal of Management Studies, 49/2: 403-428.

Arvanitis, S., Kubli, U. and Woerter, M. (2008) 'University-industry knowledge and technology transfer in Switzerland: What university scientists think about co-operation with private enterprises', Research Policy, 37/10: 1865-1883.

Best, K., Sinell, A., Heidingsfelder, M.L. and Schraudner, M. (2016) 'The gender dimension in knowledge and technology transfer - the German case', European Journal of Innovation Management, 19/1: 2-25. http://dx.doi.org/10.1108/EJIM-07-2015-0052

Bekkers, R. and Bodas Freitas, I.M. (2008) 'Analysing knowledge transfer channels between universities and industry: To what degree do sectors also matter?', Research Policy, 37/10: 1837-1853

Bercovitz, J. and Feldman, M. (2008) 'Academic Entrepreneurs: Organizational Change at the Individual Level’, Organization Science, 19/1: 69-89. 
Bertolotti, F., Mattarelli, E., Vignoli, M. and Macrì, D.M. (2015) 'Exploring the relationship between multiple team membership and team performance: The role of social networks and collaborative technology', Research Policy, 44/4: 911-924.

Boardman, P. C., \& Ponomariov, B. L. (2007) 'Reward systems and Nsf University Research Centers: The impact of tenure on University Scientists' valuation of applied and commercially relevant research', Journal of Higher Education, 78/1: 51-70.

Bonaccorsi, A., \& Daraio, C. (2003) 'Age effects in scientific productivity. The case of the Italian National Research Council (CNR)’, Scientometrics, 58/1, 35-48.

Bozeman, B. (2000) 'Technology transfer and public policy: a review of research and theory', Research Policy, 29/4-5: 627-655.

Bozeman, B. and Corley, E. (2004) 'Scientific and Technical Human Capital: Science Careers and Networks as Knowledge Assets’, Research Policy, 33/4: 599-616.

Bozeman, B. Rimes, H. and Youtie, J. (2015) 'The evolving state-of-the-art in technology transfer research: Revisiting the contingent effectiveness model', Research Policy, 44/1: 3449.

Bozeman, B. and Gaughan, M. (2007) 'Impacts of grants and contracts on academic researchers’ interactions with industry’, Research Policy, 36/5: 694-707.

Bozeman, B. and Gaughan, M. (2011) 'How do men and women differ in research collaborations? An analysis of the collaborative motives and strategies of academic researchers', Research Policy, 40/10: 1393-1402.

Chavarro, D., Tang, P. and Rafols, I. (2014) 'Interdisciplinarity and research on local issues: evidence from a developing country’, Research Evaluation, 23/3: 195-209.

CSIC (2012) Memoria anual 2011. Madrid: CSIC.

Cummings, J.N. (2005) 'Collaborative Research Across Disciplinary and Organizational Boundaries’, Social Studies of Science, 35/5: 703-722.

D'Este, P. and Patel, P. (2007) 'University-industry linkages in the UK: What are the factors underlying the variety of interactions with industry?', Research Policy, 36/9: 12951313.

D’Este, P., Mahdi, S, Neely, A. and Rentocchini, F. (2012) 'Inventors and entrepreneurs in academia: What types of skills and experience matter?’, Technovation, 32/5: 293-303

D'Este, P. and Perkmann, M. (2011) 'Why do academics engage with industry? The entrepreneurial university and individual motivations', The Journal of Technology Transfer, 36/3: 316-339.

De Fuentes, C. and Dutrénit, G. (2012) 'Best channels of academia-industry interaction for long-term benefit’ Research Policy, 41/9: 1666-1682. 
Dietz, J.S., Bozeman, B. (2005) 'Academic careers, patents, and productivity: industry experience as scientific and technical human capital', Research Policy, 34/3, 349-367.

Esko, T., Tuunainen, J. and Miettinen, R. (2012) 'Social impact and forms of interaction between university research and society in humanities and social sciences'. International Journal of Contemporary Sociology, 49/1: 17-45.

Garner, J.G., Porter, A.L., Newman, N.C., Crowl, T.A. (2012) 'Assessing research network and disciplinary engagement changes induced by an NSF program', Research Evaluation 21/2, 89-104.

Geuna, A and Muscio, A. (2009) 'The Governance of University Knowledge Transfer: A Critical Review of the Literature', Minerva, 47/1: 93-114.

Giuliani, E., Morrison, A., Pietrobelli, C., Rabellotti, R. (2010) 'Who are the researchers that are collaborating with industry? An analysis of the wine sectors in Chile, South Africa and Italy', Research Policy, 39, 748-761.

Good, D., Michel, E.J. (2013) 'Individual ambidexterity: exploring and exploiting in dynamic contexts’, The Journal of Psychology, 147/5: 435-453.

Göransson, Bo, Maharajh, R. and Schmoch, U. (2009) 'New activities of universities in transfer and extension: multiple requirements and manifold solutions', Science and Public Policy, 36/2: 157-164.

Gulbrandsen, M. and Smeby, J.C. (2005) 'Industry funding and university professors' research performance', Research Policy, 34/6: 932-950.

Gupta, N., Kemelgor, C., Fuchs, S., Etzkowitz, H. (2005) 'Triple burden on women in science. A cross-cultural analysis’, Current Science, 89/8, 1382-1386.

Halilem, N., Amara, N., \& Landry, R. (2010) 'Is the academic Ivory Tower becoming a managed structure? A nested analysis of the variance in activities of researchers from natural sciences and engineering in Canada’ Scientometrics, 86/2: 431-448.

Haeussler, C. and Colyvas, J.A. (2011) 'Breaking the Ivory Tower: Academic Entrepreneurship in the Life Sciences in UK and Germany’, Research Policy, 40/1: 41-54.

Hughes, A., Kitson, M., Probert, J., Bullock, A. and Milner, I. (2011) 'Hidden connections: Knowledge exchange between the arts and humanities and the private, public and third sectors'. Cambridge, UK: Arts and Humanities Research Council and Centre for Business Research, <http://www.ahrc.ac.uk/News-and-Events/Publications/Documents/HiddenConnections.pdf $>$ accessed 17 September 2013.

Ibarra, H. (2003) 'Homophily and differential returns: Sex differences in network structure and access in an advertising firm', Administrative Science Quarterly, 37/3: 422-47. 
Iorio, R., Labory, S. and Rentocchini, F. (2017) 'The importance of pro-social behaviour for the breadth and depth of knowledge transfer activities: An analysis of Italian academic scientists', Research Policy, http://dx.doi.org/10.1016/j.respol.2016.12.003.

Jacobs, J.A. and Frickel, S. (2009) 'Interdisciplinarity: A Critical Assessment', Annual Review of Sociology, 35: 43-65.

Jacobson, N., Butterill, D. and Goering, P. (2004) 'Organizational Factors that Influence University-Based Researchers’ Engagement in Knowledge Transfer Activities’, Science Communication, 5/3: 246-259.

Jensen, P. and Lutkouskaya, K. (2014) 'The many dimensions of laboratories' interdisciplinarity’, Scientometrics, 98/1: 619-631.

Kyvik, S. (1995) 'Are big university departments better than small ones?', Higher Education, 30/3: 295-304.

Lam, A. (2011) 'What motivates academic scientists to engage in research commercialization: ‘Gold', 'ribbon’ or ‘puzzle'?', Research Policy, 40/10: 1354-1368.

Landry, R., Amara, N. and Lamari, M. (2001) 'Utilization of social science research knowledge in Canada’, Research Policy, 30/2: 333-349.

Landry, R., Amara, N. and Ouimet, M. (2007) 'Determinants of knowledge transfer: evidence from Canadian university researchers in natural sciences and engineering', The Journal of Technology Transfer, 32/6: 561-592.

Landry, R., Saïhi, M, Amara, N. and Ouimet, M. (2010) 'Evidence on how academics manage their portfolio of knowledge transfer activities', Research Policy, 39: 1387-1403.

Laredo, P. (2007) 'Revisiting the Third Mission of Universities: Toward a Renewed Categorization of University Activities?’ Higher Education Policy, 20/4: 441-456.

Larivière, V. and Gingras, Y. (2010) 'The impact factor's Matthew Effect: A natural experiment in bibliometrics', Journal of the American Society for Information Science and Technology, 61/2: 424-427. doi:10.1002/asi.21226.

Lawson, C., and Sterzi, V. (2014) 'The role of early-career factors in the formation of serial academic inventors’, Science and Public Policy, 41/4: 464-479.

Lee, Y.S. (1996) 'Technology transfer and the research university: a search for the boundaries of university-industry collaboration', Research Policy, 25/6: 843-863.

Lee, S. and Bozeman, B. (2005) 'The Impact of Research Collaboration on Scientific Productivity’, Social Studies of Science, 35/5: 673-702.

Link, A.N., Siegel, D.S. and Bozeman, B. (2007) 'An empirical analysis of the propensity of academics to engage in informal university technology transfer', Industrial and Corporate Change, 16/4: 641-655. 
Louis, K.S., Blumenthal, D., Gluck, M.E., Stoto, M.A. (1989) 'Entrepreneurs in academe: an exploration of behaviors among life scientists', Administrative Science Quarterly, 34/1, 110 131.

Lyall, C., Bruce, A., Marsden, W., Meagher, L. (2013) 'The role of funding agencies in creating interdisciplinary knowledge’, Science and Public Policy, 40: 62-71.

Manjarrés-Henríquez, L., Gutiérrez-Gracia, A. and Vega-Jurado, J. (2008) 'Coexistence of university - industry relations and academic research: Barrier to or incentive for scientific productivity', Scientometrics, 76/3: 561-576.

Manjarrés-Henríquez, L., Gutiérrez-Gracia, A., Carrión-García, A. and Vega-Jurado, J. (2009) 'The effects of University-Industry Relationships and academic research on scientific performance: synergy or substitution?', Research in Higher Education, 50: 795-811.

Meyer-Krahmer, F. and Schmoch, U. (1998) 'Science-based technologies: universityindustry interactions in four fields', Research policy, 27/8: 835-851.

Miller, K., McAdam, M. and McAdam, R. (2014) 'The changing university business model: a stakeholder perspective’, R\&D Management, 44/3: 265-287.

Molas-Gallart, J., Rafols, I. and Tang, P. (2014) 'On the relationship between interdisciplinarity and impact: different modalities of interdisciplinarity lead to different types of impact', Journal of Science Policy and Research Management, 29: 69-89.

Mowery, D. C. (2011) 'Learning from one another? International policy "emulation" and university-industry technology transfer’, Industrial and Corporate Change, 20/6: 1827-1853.

Murray, F. and Graham, L. (2007) 'Buying science and selling science: gender differences in the market for commercial science’, Industrial and Corporate Change, 16/4: 657-689. doi:10.1093/icc/dtm021

OECD (1996) The Knowledge-based Economy. Paris: OECD

O’Kane, C., Mangematin, V., Geoghegan, W. and Fitzgerald, C. (2015) 'University technology transfer offices: The search for identity to build legitimacy', Research Policy, 44/2: 421-437.

Olmos-Penuela, J., Benneworth, P. and Castro-Martinez, E. (2104a) 'Are 'STEM from Mars and SSH from Venus'?: Challenging disciplinary stereotypes of research's social value'. Science and Public Policy, 41/3: 384-400.

Olmos-Penuela, J., Molas-Gallart, J. and Castro-Martinez, E. (2014b) 'Informal collaborations between social sciences and humanities researchers and non-academic partners'. Science and Public Policy, 41/4: 493-506.

Olmos-Peñuela, J, Castro-Martínez, E. and D'Este, P. (2014c) 'Knowledge transfer activities in social sciences and humanities: Explaining the interactions of research groups with nonacademic agents', Research Policy, 43/4: 696-706. 
Olmos-Peñuela, J, Benneworth, P. and Castro-Martínez, E. (2015). 'What Stimulates Researchers to Make Their Research Usable? Towards an 'Openness' Approach', Minerva, 53/4: 381-410.

O’Leary, M.B., Mortensen, M., Woolley, A.W. (2011) 'Multiple team membership: A theoretical model of its effects on productivity and learning for individuals and teams', Academy of Management Review, 36: 461-478.

Osuna, C., Cruz-Castro, L. and Sanz-Menéndez, L. (2011) 'Overturning some assumptions about the effects of evaluation systems on publication performance’, Scientometrics, 86: 575.

Perkmann, M. and Walsh, K. (2007) 'University-industry relationships and open innovation: towards a research agenda’, International Journal of Management Reviews, 9: 259-280.

Perkmann, M., Tartari, V., McKelvey, M., Autio, E., Broström, A., D’Este, P., Fini, R., Geuna, A., Grimaldi, R., Hughes, A., Krabel, S. Kitson, M., Llerena, P., Lissoni, F., Salter, and A., Sobrero, M. (2013) 'Academic engagement and commercialisation: A review of the literature on university—industry relations’, Research Policy, 42/2: 423-442.

Philpott, K., Dooley, L., O'Reilly, C. and Lupton, G. (2011) 'The entrepreneurial university: Examining the underlying academic tensions’, Technovation, 31/4: 161-170.

Polt, W., Gassler, H., Schibany, A., Rammer, C. and Schartinger, D. (2001) 'Benchmarking industry-science relations: the role of framework conditions', Science and Public Policy, 28/4: 247-258.

Ponomariov, B. (2008) 'Effects of university characteristics on scientists' interactions with the private sector: an exploratory assessment', The Journal of Technology Transfer, 33/5: 485-503.

Porter, A.L., Cohen, A.S., David Roessner, J., Perreault, M. (2007) 'Measuring researcher interdisciplinarity', Scientometrics, 72: 117-147.

Powell, W. W., Koput, K. W., \& Smith-Doerr, L. (1996) 'Interorganizational collaboration and the locus of innovation: Networks of learning in biotechnology', Administrative Science Quarterly, 41/1: 116-145.

Powell, W.W. and Owen-Smith, J. (1998) 'Universities and the Market for Intellectual Property in the Life Sciences', Journal of Policy Analysis and Management, 17/2: 253-277.

Ramos-Vielba, I., Sánchez-Barrioluengo, M. and Woolley, R. (2016) 'Scientific research groups' cooperation with firms and government agencies: motivations and barriers', The Journal of Technology Transfer, 41/3: 558-585.

Schartinger, D., Schibany, A., Gassler, H. (2001) 'Interactive relations between universities and firms: empirical evidence for Austria’, Journal of Technology Transfer, 26, 255-268.

Schartinger, D., Rammer, C., Fischer, M.M and Fröhlich, J. (2002) 'Knowledge interactions between universities and industry in Austria: sectoral patterns and determinants', Research Policy, 31/3: 303-328. 
Schmickl, C. and Kieser, A. (2008) 'How much do specialists have to learn from each other when they jointly develop radical product innovations?', Research Policy, 37/6-7: 11481163.

Schultz, C., Schreyoegg, J., von Reitzenstein, C. (2013) 'The moderating role of internal and external resources on the performance effect of multitasking: Evidence from the R\&D performance of surgeons', Research Policy, 42/8: 1356-1365.

Schultz, C., Schreyoegg, J. and Reitzenstein, C.V. (2013) 'The moderating role of internal and external resources on the performance effect of multitasking: Evidence from the R\&D performance of surgeons', Research Policy 42/8: 1356-1365.

Stephan, P., Levin, S.G. (1992) Striking the Mother Lode in Science: The Importance of Age, Place and Time. New York: Oxford University Press.

Tartari, V., and Breschi, S. (2012) 'Set them free: scientists' evaluations of the benefits and costs of university-industry research collaboration', Industrial and Corporate Change, 21/5: 1117-1147.

Tartari, V., Perkmann, M. and Salter, A. (2014) 'In good company: The influence of peers on industry engagement by academic scientists’, Research Policy, 42/8: 1189-1203.

UNESCO (2005) Towards Knowledge Societies. UNESCO Publishing: Paris. http://www.unesco.org/new/en/communication-and-information/resources/publications-andcommunication-materials/publications/full-list/towards-knowledge-societies-unesco-worldreport/. Accessed 28 September 2016.

Vega-Jurado, J., Gutiérrez-Gracia, A., Fernández-de-Lucio, I. and Manjarrés-Henríquez, L. (2008) 'The effect of external and internal factors on firms' product innovation”, Research Policy, 37/4: 616-632.

Yegros-Yegros, A., Rafols, I. and D’Este, P. (2015) 'Does Interdisciplinary Research Lead to Higher Citation Impact? The Different Effect of Proximal and Distal Interdisciplinarity', PLOS ONE, 10/8: 1-21.

Weckowska, D.M. (2015) 'Learning in university technology transfer offices: transactionsfocused and relations-focused approaches to commercialization of academic research', Technovation, 41-42: 62-74.

Zucker, L.G., Darby, M.R., Brewer, M.B., (1998) 'Intellectual human capital and the birth of US Biotechnology enterprises’, The American Economic Review, 88/1: 290-306. 
Table 1: Response rates by field of science $(\mathrm{N}=1295)$

\begin{tabular}{lccc}
\hline Scientific field & Surveyed population & Valid responses & Response rate \\
\hline Agricultural Sciences & 365 & 192 & $52.6 \% *$ \\
Biology \& Biomedicine & 547 & 199 & $36.4 \%$ \\
Chemistry Science \& Technology & 381 & 181 & $47.5 \% *$ \\
Food Science \& Technology & 246 & 119 & $48.4 \% *$ \\
Materials Science \& Technology & 433 & 164 & $37.9 \%$ \\
Natural Resources & 482 & 196 & $40.7 \%$ \\
Physical Science \& Technology & 424 & 164 & $38.7 \%$ \\
Social Sciences \& Humanities & 321 & 91 & $28.3 \% *$ \\
\hline Total & 3,199 & 1,295 & $40 \%$ \\
\hline
\end{tabular}

* They significantly differ (chi-square $\mathrm{p}<0.05$ ) when compared to the overall response rate of the other fields in our sample. 
Table 2: Correspondence between activities and entities from the questionnaire and KTE mechanisms and actors used in this study.

\section{Panel A. KTE mechanismsvariety}

Creation of a new firm in partnership.

Participation in the creation of a new centre or joint unit of R\&D.

Collaborative research funded by international programs.

Contract research.

Collaborative research funded by a Spanish public program.

FORMAL

License of patents (or other types of intellectual property protection).

Courses and specialised training activities taught by the CSIC.

Use of CSIC infrastructures or equipment by this entity.

Consultancy through committees and expert meetings.

Temporary stay of a person of your team outside the academy.

Training of postgraduates outside the academy.

Technical services, technical reports or technological support.

INFORMAL

Participation in diffusion activities in professional environment.

Occasional contacts or consultations.

\begin{tabular}{l|c}
\hline Panel B. Users variety & \\
\hline $\begin{array}{l}\text { National private sector. } \\
\text { International private sector. }\end{array}$ & PRIVATE SECTOR \\
\hline $\begin{array}{l}\text { National public organizations. } \\
\text { International public organizations. }\end{array}$ & PUBLIC SECTOR \\
\hline NGOs. & NGOs \\
\hline
\end{tabular}


Table 3: Factor analysis results and internal reliability coefficients (Chronbach’s alpha)

\begin{tabular}{lccc}
\hline & $\begin{array}{c}\text { Factor 1: } \\
\text { Advancing } \\
\text { research }\end{array}$ & $\begin{array}{c}\text { Factor 2: } \\
\text { Expanding } \\
\text { network }\end{array}$ & $\begin{array}{c}\text { Factor 3: } \\
\text { Obtaining } \\
\text { income }\end{array}$ \\
\hline $\begin{array}{l}\text { To obtain additional funds for research } \\
\text { To be updated about the topics of interest for non- }\end{array}$ & 0.159 & 0.137 & $\mathbf{0 . 4 4 2}$ \\
academic actors & 0.204 & $\mathbf{0 . 5 9 5}$ & 0.125 \\
To be part of a professional network & 0.360 & $\mathbf{0 . 4 2 3}$ & 0.199 \\
To test empirically the validity of the own research & 0.230 & $\mathbf{0 . 5 7 1}$ & 0.089 \\
To obtain information or material to develop their & $\mathbf{0 . 6 2 7}$ & 0.267 & 0.142 \\
current research & & & \\
To explore additional research topics & $\mathbf{0 . 6 4 5}$ & 0.228 & 0.136 \\
To have access to non-academic expertise & 0.360 & $\mathbf{0 . 4 7 4}$ & 0.055 \\
To have access to equipment and infrastructures to & $\mathbf{0 . 5 3 2}$ & 0.143 & 0.346 \\
perform research & & & \\
To improve personal income & 0.230 & 0.222 & $\mathbf{0 . 2 8 0}$ \\
To obtain grants and scholarships for PhD students & 0.305 & 0.116 & $\mathbf{0 . 5 1 9}$ \\
\hline Chronbach alpha & 0.537 & 0.720 & 0.705 \\
\hline
\end{tabular}


Figure 1: Engagement in KTE mechanisms

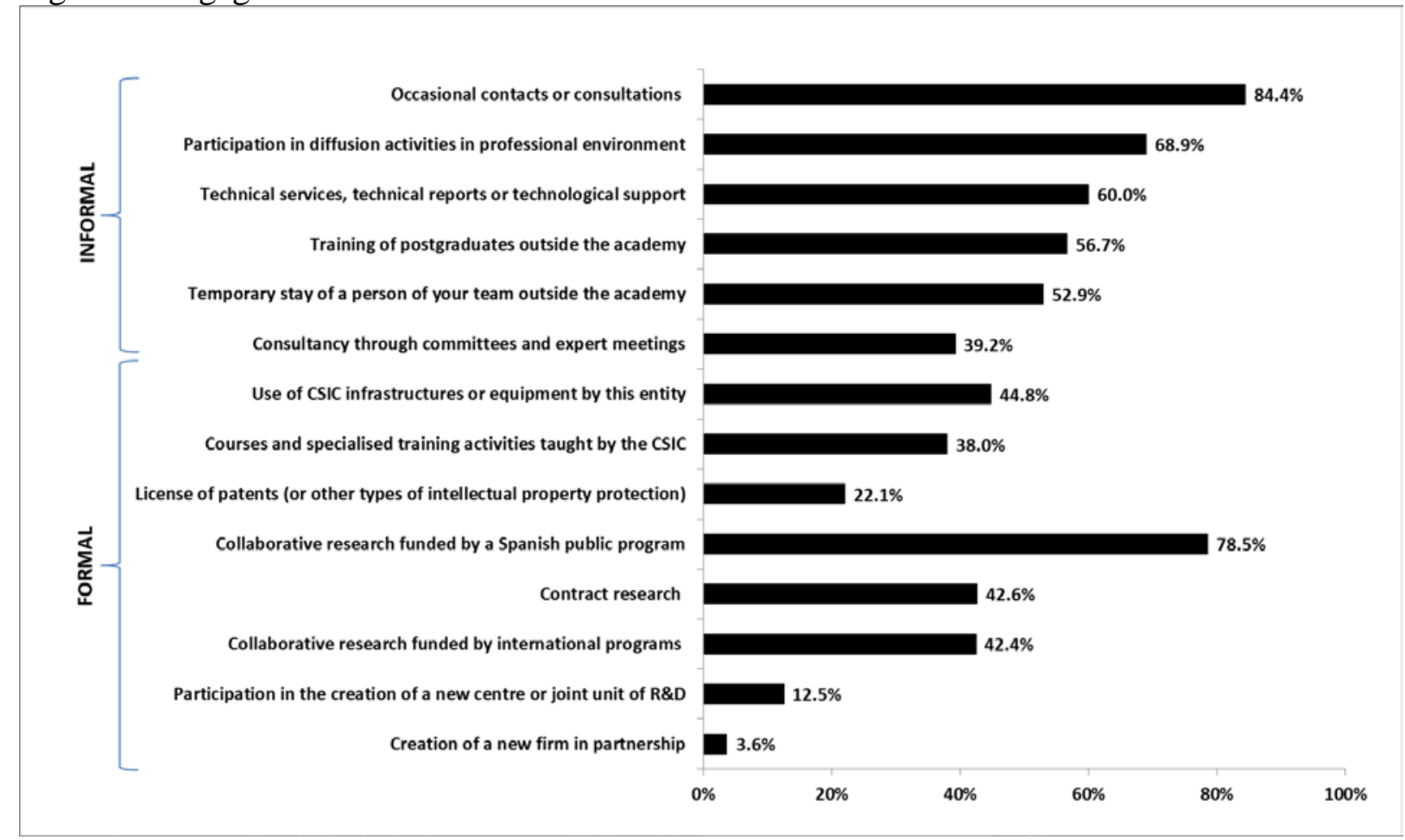


Figure 2: Engagement by type of user involved

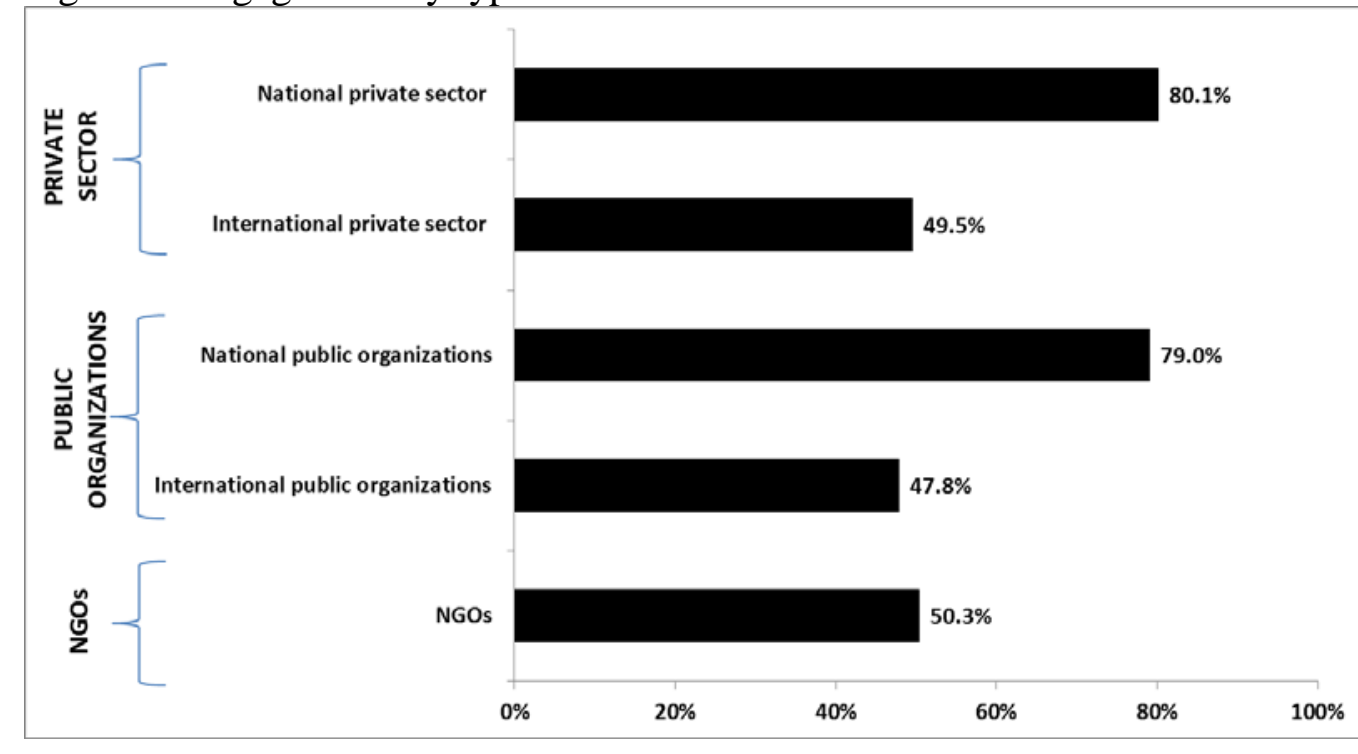


Table 4: Descriptive statistics of the individual-level antecedents of engagement in KTE mechanisms

\begin{tabular}{|c|c|c|c|c|c|}
\hline Variable & Mean & Std. Dev. & Min. & Max. & Obs. \\
\hline \multicolumn{6}{|l|}{ Individual capacities } \\
\hline Interdisciplinarity frequent & \multicolumn{5}{|c|}{$391(30.01 \%)$} \\
\hline Interdisciplinarity occasionally & \multicolumn{5}{|c|}{$638(48.96 \%)$} \\
\hline Interdisciplinarity never or hardly ever & \multicolumn{5}{|c|}{$274(21.03 \%)$} \\
\hline Multitasking: HHindex (1-HHindex) & 0.489 & 0.167 & 0 & 0.795 & 1,249 \\
\hline \multicolumn{6}{|l|}{ Training and career trajectories } \\
\hline Previous experience: Private Sector (years) & 0.758 & 2.761 & 0 & 32 & 1,195 \\
\hline Previous experience: Public organizations (years) & 0.698 & 3.224 & 0 & 45 & 1,197 \\
\hline Previous experience: Universities (years) & 3.366 & 4.972 & 0 & 34 & 1,162 \\
\hline Rank: Tenured scientist & \multicolumn{5}{|c|}{$579(44.33 \%)$} \\
\hline Rank: Scientific researcher & \multicolumn{5}{|c|}{$431(33 \%)$} \\
\hline Rank: Research professor & \multicolumn{5}{|c|}{$296(22.66 \%)$} \\
\hline \multicolumn{6}{|l|}{ Research performance } \\
\hline Sexenios & 2.704 & 1.543 & 0 & 6 & 1,285 \\
\hline Supervision experience & 2.274 & 1.864 & 0 & 17 & 1,253 \\
\hline \multicolumn{6}{|l|}{ Motivations } \\
\hline Advancing research & -0.032 & 0.749 & -2.583 & 1.291 & 1,253 \\
\hline Expanding network & -0.028 & 0.733 & -2.800 & 1.637 & 1,253 \\
\hline Obtaining Income & -0.016 & 0.633 & -2.473 & 1.150 & 1,253 \\
\hline \multicolumn{6}{|l|}{ Controls } \\
\hline Size research group & 8.693 & 10.072 & 0 & 300 & 1,146 \\
\hline$\%$ competitive funds & 82.660 & 22.289 & 0 & 100 & 1,257 \\
\hline Gender: female & \multicolumn{5}{|c|}{$452(35.18 \%)$} \\
\hline
\end{tabular}


Table 5: Individual antecedents of KTE mechanisms and users variety

\begin{tabular}{|c|c|c|c|c|}
\hline & \multicolumn{3}{|c|}{ Mechanism variety } & \multirow{2}{*}{ Users variety } \\
\hline & Total & Formal & Informal & \\
\hline \multicolumn{5}{|l|}{ Individual capacities } \\
\hline \multicolumn{5}{|c|}{ Interdisciplinarity (Ref. cat.: Never or Hardly ever) } \\
\hline Frequently & $\begin{array}{c}0.179 * * \\
(0.059)\end{array}$ & $\begin{array}{c}0.154^{* *} \\
(0.059)\end{array}$ & $\begin{array}{c}0.115^{* * *} \\
(0.029)\end{array}$ & $\begin{array}{c}0.123 * * * \\
(0.031)\end{array}$ \\
\hline Occasionally & $\begin{array}{l}0.124 * \\
(0.057)\end{array}$ & $\begin{array}{c}0.107 \\
(0.058)\end{array}$ & $\begin{array}{c}0.073 * * \\
(0.028)\end{array}$ & $\begin{array}{l}0.073 * \\
(0.036)\end{array}$ \\
\hline Multitasking & $\begin{array}{c}0.757 * * * \\
(0.124)\end{array}$ & $\begin{array}{c}0.594 * * * \\
(0.111)\end{array}$ & $\begin{array}{c}0.508 * * * \\
(0.082)\end{array}$ & $\begin{array}{c}0.532 * * * \\
(0.057)\end{array}$ \\
\hline \multicolumn{5}{|l|}{ Training and career trajectories } \\
\hline \multicolumn{5}{|l|}{ Previous experience (ln years) } \\
\hline Private sector & $\begin{array}{c}0.019 \\
(0.020)\end{array}$ & $\begin{array}{c}0.012 \\
(0.021)\end{array}$ & $\begin{array}{c}0.017 \\
(0.019)\end{array}$ & $\begin{array}{c}0.008 \\
(0.018)\end{array}$ \\
\hline Universities & $\begin{array}{c}-0.024 \\
(0.023)\end{array}$ & $\begin{array}{c}-0.029 \\
(0.019)\end{array}$ & $\begin{array}{c}-0.007 \\
(0.015)\end{array}$ & $\begin{array}{c}-0.001 \\
(0.014)\end{array}$ \\
\hline Public organizations & $\begin{array}{c}0.098 * * * \\
(0.026)\end{array}$ & $\begin{array}{c}0.068 * * \\
(0.026)\end{array}$ & $\begin{array}{c}0.074 * * * \\
(0.019)\end{array}$ & $\begin{array}{c}0.043 * * \\
(0.013)\end{array}$ \\
\hline \multicolumn{5}{|l|}{ Rank (Ref. cat.: Tenured scientist) } \\
\hline Scientific researcher & $\begin{array}{c}0.053 \\
(0.068)\end{array}$ & $\begin{array}{c}0.068 \\
(0.062)\end{array}$ & $\begin{array}{c}0.007 \\
(0.042)\end{array}$ & $\begin{array}{c}0.057^{*} \\
(0.028)\end{array}$ \\
\hline Research professor & $\begin{array}{c}0.134 \\
(0.086)\end{array}$ & $\begin{array}{c}0.121 \\
(0.072)\end{array}$ & $\begin{array}{c}0.070 \\
(0.060)\end{array}$ & $\begin{array}{c}0.101 * * * \\
(0.016)\end{array}$ \\
\hline \multicolumn{5}{|l|}{ Research performance } \\
\hline Sexenios (ln) & $\begin{array}{l}-0.036 \\
(0.049)\end{array}$ & $\begin{array}{c}-0.027 \\
(0.044)\end{array}$ & $\begin{array}{l}-0.015 \\
(0.036)\end{array}$ & $\begin{array}{c}-0.059 * * \\
(0.019)\end{array}$ \\
\hline Supervision experience (ln) & $\begin{array}{c}0.028 \\
(0.033)\end{array}$ & $\begin{array}{c}-0.012 \\
(0.028)\end{array}$ & $\begin{array}{l}0.052 * \\
(0.026)\end{array}$ & $\begin{array}{c}0.039 * * * \\
(0.006)\end{array}$ \\
\hline \multicolumn{5}{|l|}{ Motivations } \\
\hline Advancing research & $\begin{array}{l}0.050 * \\
(0.023)\end{array}$ & $\begin{array}{c}0.047 * * \\
(0.015)\end{array}$ & $\begin{array}{c}0.025 \\
(0.019)\end{array}$ & $\begin{array}{c}0.031^{* *} \\
(0.010)\end{array}$ \\
\hline Expanding network & $\begin{array}{c}0.124 * * * \\
(0.030)\end{array}$ & $\begin{array}{c}0.102 * * * \\
(0.024)\end{array}$ & $\begin{array}{c}0.082 * * \\
(0.024)\end{array}$ & $\begin{array}{c}0.060 * * * \\
(0.015)\end{array}$ \\
\hline Obtaining income & $\begin{array}{c}0.057 * * \\
(0.023)\end{array}$ & $\begin{array}{c}0.037 \\
(0.022)\end{array}$ & $\begin{array}{c}0.051^{* *} \\
(0.017)\end{array}$ & $\begin{array}{c}0.025 \\
(0.015)\end{array}$ \\
\hline \multicolumn{5}{|l|}{ Controls } \\
\hline Size research group (ln) & $\begin{array}{c}0.067 \\
(0.045)\end{array}$ & $\begin{array}{c}0.099 * * * \\
(0.028)\end{array}$ & $\begin{array}{c}0.018 \\
(0.044)\end{array}$ & $\begin{array}{c}0.036 * * \\
(0.015)\end{array}$ \\
\hline \% competitive funds (ln) & $\begin{array}{c}-0.077 * \\
(0.040)\end{array}$ & $\begin{array}{c}-0.064 \\
(0.040)\end{array}$ & $\begin{array}{l}-0.050 * \\
(0.023)\end{array}$ & $\begin{array}{l}-0.039 * \\
(0.017)\end{array}$ \\
\hline Gender (Ref. cat.: Male) & $\begin{array}{c}-0.075 * * * \\
(0.021)\end{array}$ & $\begin{array}{c}-0.098 * * * \\
(0.017)\end{array}$ & $\begin{array}{l}-0.014 \\
(0.023)\end{array}$ & $\begin{array}{c}-0.062 * * \\
(0.021)\end{array}$ \\
\hline Scientific field & Included & Included & Included & Included \\
\hline Constant & $\begin{array}{c}0.811 * * * \\
(0.132) \\
\end{array}$ & $\begin{array}{c}0.340 * * \\
(0.142)\end{array}$ & $\begin{array}{c}0.605^{* * *} * \\
(0.079) \\
\end{array}$ & $\begin{array}{c}0.429 * * * \\
(0.068) \\
\end{array}$ \\
\hline $\begin{array}{l}\mathrm{R} 2 \\
\mathrm{~N}\end{array}$ & $\begin{array}{c}0.289 \\
764\end{array}$ & $\begin{array}{c}0.270 \\
764\end{array}$ & $\begin{array}{c}0.236 \\
764\end{array}$ & $\begin{array}{c}0.283 \\
752\end{array}$ \\
\hline
\end{tabular}

Note: ${ }^{*} \mathrm{p}<.1,{ }^{* *} \mathrm{p}<.05,{ }^{* * *} \mathrm{p}<.01$. Standard errors in parentheses 
Annex I: Correlation matrix and variance inflator factor (VIF)

\begin{tabular}{|c|c|c|c|c|c|c|c|c|c|c|c|c|c|c|c|}
\hline & 1. & 2. & 3. & 4. & 5. & 6. & 7. & 8. & 9. & 10. & 11. & 12. & 13. & 14. & VIF \\
\hline 1. Interdisciplinarity & 1 & & & & & & & & & & & & & & 1.16 \\
\hline 2. Multitasking & $-0.253 * * *$ & & & & & & & & & & & & & & 1.18 \\
\hline 3. Previous experience private sector & -0.001 & 0.029 & 1 & & & & & & & & & & & & 1.05 \\
\hline 4. Previous experience universities & -0.037 & 0.019 & 0.006 & & & & & & & & & & & & 1.05 \\
\hline 5. Previous experience public organizations & -0.035 & $0.071^{* *}$ & $0.116 * * *$ & $0.072 * *$ & 1 & & & & & & & & & & 1.04 \\
\hline 6. Rank & -0.034 & $0.128^{* * *}$ & -0.043 & 0.038 & -0.005 & 1 & & & & & & & & & 1.89 \\
\hline 7. Sexenios (In) & 0.043 & 0.012 & $-0.05 * 1$ & $0.059 *$ & -0.022 & $0.62^{* * *}$ & 1 & & & & & & & & 1.80 \\
\hline 8. Supervision experience (ln) & $-0.072^{* *}$ & $0.178^{* * *}$ & 0.004 & $0.064^{* *}$ & -0.029 & $0.225^{* * *}$ & $0.089 * * *$ & & & & & & & & 1.20 \\
\hline 9. Advanci & $-0.089 * * *$ & 0.033 & $0.075 * *$ & -0.001 & $0.058 * *$ & $-0.064 * *$ & -0.007 & 0.030 & 1 & & & & & & 1.37 \\
\hline 10. Expan & $-0.185^{* * *}$ & $0.167^{* * *}$ & 0.038 & $-0.058^{*}$ & 0.018 & -0.040 & $-0.103^{* * *}$ & -0.008 & $0.331^{* * *}$ & 1 & & & & & 1.29 \\
\hline 11. Obtair & -0.008 & $0.088 * * *$ & 0.006 & -0.006 & 0.013 & -0.026 & -0.004 & $0.115 * * *$ & 0.356 *** & $0.133^{* * * *}$ & 1 & & & & 1.31 \\
\hline 12. \% con & $27^{7 * * * *}$ & $-0.083^{* *}$ & $0666^{* *}$ & 012 & -0.050 & 0.025 & $0.081^{* * *}$ & $0.113 * * *$ & $\begin{array}{l}-0.019 \\
-\end{array}$ & $-0.117^{* * * *}$ & 0.036 & & & & 14 \\
\hline 13. Size res & $-0.128^{* * *}$ & $0.106 * * *$ & .010 & 31 & 0.028 & $0.106 * * *$ & -0.009 & $0.225 * * *$ & 0.027 & $0.075 * *$ & 0.025 & -0.016 & & & 1.16 \\
\hline 4. Gender & 0.004 & $\begin{array}{l}.1 .022 \\
-0.022\end{array}$ & $-0.060^{* * *}$ & $103^{* * * *}$ & 0.010 & $-0.162 * * *$ & $-0.081^{* * * *}$ & -0.024 & $0.172 * * *$ & $0.149 * * *$ & 0.143 & $0.069 * *$ & 003 & & 1.13 \\
\hline 15. Scientific field & $\begin{array}{l}-0.082^{* * * *} \\
-\end{array}$ & $\begin{array}{l}-0.022 * * \\
0.081 * * *\end{array}$ & $\begin{array}{l}-0.000 \\
0.027\end{array}$ & $\begin{array}{l}-0.035 \\
0.032\end{array}$ & $\begin{array}{l}0.027 \\
0.027\end{array}$ & $\begin{array}{l}-0.102 \\
-0.032 \\
\end{array}$ & $\begin{array}{l}-0.001 \\
-0.133 * * *\end{array}$ & $\begin{array}{l}-0.024 \\
-0.147 * * *\end{array}$ & $\begin{array}{l}-1.023 \\
-0.023\end{array}$ & 0.028 & $\begin{array}{l}-0.108^{* * * *} \\
-\end{array}$ & $\begin{array}{l}-0.053^{*} \\
-\end{array}$ & $0.110^{* * * *}$ & $\begin{array}{l}1 \\
-0.051 *\end{array}$ & 1.12 \\
\hline
\end{tabular}

